\title{
Effect of a p210 multipeptide vaccine associated with imatinib or interferon in patients with chronic myeloid leukaemia and persistent residual disease: a multicentre observational trial
}

M Bocchia, S Gentili, E Abruzzese, A Fanelli, F Iuliano, A Tabilio, M Amabile, F Forconi, A Gozzetti, D Raspadori, S Amadori, F Lauria

\section{Summary}

Background Although imatinib is the standard treatment for chronic myeloid leukaemia, not all patients reach complete cytogenetic remission (CCR) and most maintain detectable disease at the molecular level. We investigated whether a vaccine targeting the BCR-ABL-derived p210 fusion protein was an active and specific immunotherapy.

Methods We recruited 16 patients who had chronic myeloid leukaemia (with the b3a2 fusion point of p210), stable residual disease, a minimum treatment of 12 months of imatinib or 24 months of interferon alfa, and no further reduction of residual disease for at least 6 months preceding enrolment. They were given six vaccinations with a peptide vaccine derived from the sequence p210-b3a2 plus molgramostim and QS-21 as adjuvants (CMLVAX100) before assessment of immunological and disease response, which included detecting amounts of b3a2 transcripts by standardised quantitative real-time reverse-transcriptase PCR.

Results Of ten patients on imatinib, nine started CMLVAX100 having had a median of 10 months' stable cytogenetic disease (median 10\% Philadelphia-chromosome-positive metaphases), whereas one started in stable CCR. All patients' cytogenetic responses improved after six vaccinations, with five reaching CCR. Notably, three of these five patients also had undetectable amounts of b3a2 transcript $\left(B C R-A B L: \beta_{2}\right.$ microglobulin ratio $\left.<0 \cdot 00001\right)$. Six patients on interferon alfa treatment with a median of 17 months' stable residual disease (median $13 \%$ Philadelphiachromosome-positive cells) were also vaccinated. All but one had improved cytogenetic responses, and two reached CCR. Overall, we recorded peptide-specific delayed-type hypersensitivity (in 11 of 16 patients), CD4 cell proliferation (13 of 14 assessed), and interferon $\gamma$ production (five of five assessed).

Interpretation Addition of CMLVAX100 to conventional treatment in patients with chronic myeloid leukaemia might favour further reduction of residual disease and increase the number of patients reaching a molecular response.

\section{Introduction}

Chronic myeloid leukaemia is a clonal disease of the haemopoietic stem cell, in which a reciprocal translocation, $\mathrm{t}(9 ; 22)(\mathrm{q} 34 ; \mathrm{q} 11)$, forms the Philadelphia chromosome and creates a new fusion gene, $B C R-A B L .{ }^{1}$ This chimeric gene is translated into a $210 \mathrm{kDa}$ protein (p210), which has abnormal tyrosine-kinase activity that is central to the pathogenesis of the disease. ${ }^{2,3}$ Treatment of chronic myeloid leukaemia has been notably improved by imatinib (Glivec, Novartis), a potent, tyrosine-kinase inhibitor that blocks the kinase activity of p210, thus inhibiting proliferation of Philadelphiachromosome-positive progenitors. ${ }^{4}$

In chronic-phase patients treated with imatinib, the kinetics of response (especially the cytogenetic response) are rapid most of the time, with major and even complete cytogenetic remission (CCR) seen within 6-12 months of treatment., ${ }^{5,6}$ However, molecular remissions are rare, especially in pretreated patients, and obvious resistance to imatinib as well as loss of response during treatment is of great concern. ${ }^{-9}$ However, despite the fact that imatinib is the most effective debulking therapy for chronic-phase patients, the eradication of residual disease (and possibly the cure) without bone-marrow transplantation still seems a difficult goal for a tyrosinekinase inhibitor approach alone. ${ }^{10}$

An alternative attempt to target the hallmark $B C R-A B L$ chimeric gene and its derived p210 fusion protein is an active specific immunotherapy (eg, a vaccine). In fact, because of the unique aminoacid sequence of p210 at the fusion point, the protein is a tumour-specific antigen to which an immune response can be induced. We and other researchers have shown that peptides derived from the p210 fusion point (b3a2) can bind several HLA class I and class II molecules and thus generate peptide-specific CD8 and CD4 T-cell responses in vitro. ${ }^{11-16}$ On the basis of these principles, two previous phase I and II vaccine trials using a mixture of five b3a2-derived peptides plus the immunological adjuvant QS- $21^{17}$ have shown peptidespecific T-cell responses, although a clear antitumour effect was not documented..$^{18,19}$ In particular, in 14 patients with b3a2 chronic-phase disease and no HLA restriction, consistent peptide-specific CD4 cell proliferation and peptide-specific CD8 interferon gamma production were recorded after vaccinations. ${ }^{19}$
Lancet 2005; 365: 657-62 See Comment page 631 Department of Haematology, Siena University, Siena, Italy (M Bocchia MD, S Gentili MD, A Fanelli PhD, F Forconi MD, A Gozzetti MD, D Raspadori PhD, Prof F Lauria MD); Department of Haematology, Roma Tor Vergata University, Rome, Italy (E Abruzzese MD, Prof S Amadori MD); Department of Haematology, Ospedale Pugliese-Ciaccio, Catanzaro, Italy (F luliano MD); Department of Haematology, Perugia University, Perugia, taly (A Tabilio MD); and Haematology and Clinical Oncology Seragnoli Institute, Bologna University, Bologna, Italy (M Amabile PhD)

Correspondence to: Dr Monica Bocchia, Department of Haematology, University of Siena, Viale Bracci 1, Siena 53100, Italy Bocchia@unisi.it 
Since effective vaccination strategies are more likely to target patients with low tumour burden, we aimed to assess the role of a p210-specific vaccine (CMLVAX100) in further reducing persistent disease in patients on conventional treatment for chronic myeloid leukaemia.

\section{Methods \\ Patients}

We started a phase-II vaccine multicentre trial in Italy, enrolling patients with b3a2-related chronic myeloid leukaemia (b3a2-CML) from four centres. Patients with persistent stable disease during conventional treatment (minimum duration of previous treatment, 12 months [imatinib]; 24 [interferon alfa]) and with at least one of the following HLA molecules were eligible for the study: HLA A3, A11, B8, DR11, DR1, or DR4. Patients were routinely assessed every 3 months for cytogenetic response, and they were described to have disease stability if no further reduction of cytogenetic residual disease was seen in at least two bone-marrow checks at previous vaccinations (ie, 6-month) and in the bone marrow at baseline. During vaccinations, patients continued their conventional treatment. Institutional review board approval and written informed consent were requested before initiation of the treatment.

\section{CMLVAX100 vaccine}

CMLVAX100 consisted of five b3a2 breakpoint-derived peptides. This included four HLA class I binding peptides derived from chronic myeloid leukaemia (100 $\mu \mathrm{g}$ per peptide; ATGFKQSSK, A11-binding; KQSSKALQR, A3-binding; HSATGFKQSSK, A3 and A11-binding; GFKQSSKAL, B8-binding), plus a 25-aminoacid peptide IVHSATGFKQSSKALQRP VASDFEP (b3a2-25) with binding motifs for HLA class II DR1, DR4, and DR11. ${ }^{13,18} 100 \mu \mathrm{g}$ QS-21 ${ }^{17}$ (Antigenics, New York, NY, USA) was added to CMLVAX100 just before vaccination.

Treatment consisted of six subcutaneous vaccinations every 2 weeks. On the day before as well as on the day of CMLVAX100 vaccination, patients received $50 \mu \mathrm{g} / \mathrm{m}^{2}$

\begin{tabular}{|c|c|c|c|c|c|c|c|c|}
\hline & \multicolumn{8}{|c|}{ Time (weeks) ${ }^{*}$} \\
\hline & Baseline & 1 & 3 & 5 & 7 & 9 & 11 & 13 \\
\hline \multicolumn{9}{|l|}{ Treatment plan } \\
\hline CMLVAX100 vaccination & & - & - & • & - & $\bullet$ & - & \\
\hline Molgramostim* & & $\bullet$ & $\bullet \bullet$ & $\bullet$ & $\bullet$ & $\bullet$ & $\bullet$ & \\
\hline \multicolumn{9}{|l|}{ Immunological assessment } \\
\hline Delayed-type hypersensitivity test & - & & & & - & & & $\bullet$ \\
\hline CD4 proliferation assay & $\bullet$ & & & & $\bullet$ & & & $\bullet$ \\
\hline PBMC interferon $\gamma$ production (ELISPOT assay) & $\bullet$ & & & & $\bullet$ & & & $\bullet$ \\
\hline \multicolumn{9}{|l|}{ Disease-response assessment } \\
\hline Bone-marrow cytogenetic analysis & - & & & & - & & & - \\
\hline Real-time quantitative $\mathrm{PCR} \dagger$ & $\bullet$ & & & & $\bullet$ & & & $\bullet$ \\
\hline \multicolumn{9}{|c|}{$\begin{array}{l}\text { PBMC=peripheral blood mononuclear cells. }{ }^{*} \text { Day before (left) and at vaccination (right). †For patients in complete cytogene } \\
\text { remission. }\end{array}$} \\
\hline
\end{tabular}

per day molgramostim (Leucomax, Shering-Plough, Italy) subcutaneously close to the vaccination site. GMCSF was used as a coimmunoadjuvant to increase peptide immunogenicity and possibly antitumour activity. ${ }^{20,21}$ For responding patients, two further boosts of vaccine after 4 and 10 months were planned (table 1 ).

\section{Specific immunological assessment}

Peptide-specific immune responses were measured at baseline and after the third and sixth vaccinations (table 1).

In-vivo delayed-type hypersensitivity was measured by skin tests with an intradermal injection of a mixture of $5 \mu \mathrm{g}$ per peptide in phosphate-buffered saline solution without QS-21 and molgramostim. Injection of phosphate-buffered saline solution alone in the opposite arm served as negative controls. A positive skin-test reaction was defined as erythema more than $10 \mathrm{~mm}$ in diameter and induration $48 \mathrm{~h}$ after injection.

Unprimed CD4 cell proliferation was measured by use of a standard ${ }^{3} \mathrm{H}$ thymidine incorporation assay. Briefly, unprimed, freshly purified (99\% pure) CD4 cells were incubated for $96 \mathrm{~h}$ at $37^{\circ} \mathrm{C}$ with $20 \mu \mathrm{g}$ peptide per $\mathrm{mL}$ under the following experimental conditions: (1) no peptide; (2) all five CMLVAX100 peptides; (3) five control peptides (including HLA-A3 and HLA-A11 binding sequences from HIV, a HLA-A2 binding sequence from influenza, and a class II RAS-derived 21-aminoacid peptide); ${ }^{13}$ (4) b3a2-25 class II binder peptide alone; (5) class II RAS-derived 21-aminoacid control peptide alone; and (6) b2a2-breakpoint-derived 25-aminoacid control peptide alone. ${ }^{11}$ Proliferation results were expressed in stimulation index values, calculated as: counts per min in the test sample (ie, CD4 cells plus peptides) divided by counts per min in the control sample (ie, CD4 cells alone).

Unprimed interferon $\gamma$ ELISPOT assays were undertaken with TEMA research reagents (Tema ricerca srl, Bologna, Italy). ${ }^{22}$ Freshly isolated peripheral blood mononuclear cells (PBMC) were added at $3 \times 10^{5}$ cells per well (in triplicate) with $20 \mu \mathrm{g} / \mathrm{mL}$ of CMLVAX100 peptides or control peptides (HIV-derived HLA A3 and A11 binder peptides, RAS peptide). The AEC (3-amino9-ethylcarbazole) staining kit (Sigma, St Louis, MO, USA) was used for colorimetric revelation of spots in the dark, and the number of spots was counted by use of an automated image analysis ELISPOT reader system (AELVIS reader system, Thornwood, NY, USA). Values were normalised to spots for every 300000 cells. We calculated the number of $\mathrm{T}$ cells producing interferon $\gamma$ in response to the addition of peptides by subtracting the number of spots seen without peptides. Means and SDs were determined for every triplicate sample.

\section{Assessment of disease response}

Before vaccination and after three and six vaccinations, patients were assessed by standard bone-marrow cytogenetic analysis for Philadelphia-chromosome- 
positive cells (minimum 30 metaphases). To assess patients reaching CCR, we used a standardised real-time quantitative (TaqMan ABI PRISM 7706, Applied Biosystems, San Francisco, CA, USA) PCR system with $\beta_{2}$ microglobulin as a housekeeping gene. ${ }^{23,24}$ Since the lowest value of detectability of this PCR method was a $B C R-A B L: \beta_{2}$ microglobulin mRNA ratio of 0.00001 , transcripts were regarded as undetectable if ratios were below this value. To confirm molecular remission, an additional, qualitative nested reverse transcriptase (RT)PCR was undertaken.

\section{Role of the funding source}

The sponsor of the study had no role in study design, data collection, data analysis, data interpretation, or writing of the report. The corresponding author had full access to all the data in the study and had final responsibility for the decision to submit for publication.

\section{Results}

Nine men and seven women with a median age of 51 years (range 45-68) were enrolled. Ten patients were on imatinib and six on interferon alfa treatment. Median duration of unchanged residual disease was 10 months (imatinib; IQR 6-18 months) and 17 (interferon alfa; 10-36 months). Of patients treated with imatinib, nine began therapy while in the late chronic phase for intolerance (two) or resistance (seven) to previous interferon-alfa-based therapies. Three had also received autologous bone-marrow transplants. At diagnosis, one patient presented with a low Sokal risk score, whereas nine were intermediate to high risk (table 2). At enrolment, they were all receiving $400 \mathrm{mg}$ imatinib per day. Six patients were receiving interferon alfa at $3 \mathrm{MU}$ per day after having been given up to $9 \mathrm{MU}$ per day plus low doses of cytosine arabinoside (AraC) as part of a randomised study. ${ }^{25}$ One patient presented with a low Sokal risk score, whereas five presented with intermediate to high risk at diagnosis (table 2).

All 16 patients underwent the first six planned vaccinations and were assessable for response to CMLVAX100. In addition to completion of the vaccine programme, the first treated patient (table 2, patient 1 on interferon alfa treatment) received the two planned boosts and four additional doses at 6-month intervals.

In our study, most patients on imatinib treatment started CMLVAX100 vaccination with a residual disease that was measurable at the cytogenetic level and with varying percentages of bone marrow Philadelphiachromosome-positive metaphases (median 10\%; table 2). At enrolment, all nine patients were on imatinib treatment for a median 15.5 months (range 12-24 months), and no further reduction of their residual disease had been documented for a median of 10 months (6-18 months) before vaccination. Patient 10 initiated vaccination after being on imatinib for 23 months and in stable CCR for 16 months. All nine patients with measurable cytogenetic disease showed a variable degree of progressive reduction of their residual Philadelphiachromosome-positive metaphases after three vaccinations (ie, 1.5 months) and after six vaccinations (ie, 3 months), with five patients reaching CCR.

Patients in CCR were then further studied for molecular response by real-time quantitative PCR and notably, three of five had undetectable transcripts after six vaccinations (table 2). These three patients underwent a qualitative

\begin{tabular}{|c|c|c|c|c|c|c|c|c|c|c|}
\hline \multirow[t]{2}{*}{$\begin{array}{l}\text { Patient number } \\
\text { (Sokal risk score) }\end{array}$} & \multirow{2}{*}{$\begin{array}{l}\text { Months of } \\
\text { treatment } \\
\text { before } \\
\text { CMLVAX100 }\end{array}$} & \multirow{2}{*}{$\begin{array}{l}\text { Months of } \\
\text { stable disease } \\
\text { before } \\
\text { CMLVAX100 } \\
\text { (range Ph+\%) }\end{array}$} & \multirow{2}{*}{$\begin{array}{l}\text { HLA class } \\
\text { molecules }\end{array}$} & \multicolumn{3}{|c|}{$\begin{array}{l}\text { CMLVAX100-specific immune } \\
\text { response after six vaccinations }\end{array}$} & \multicolumn{4}{|c|}{$\begin{array}{l}\mathrm{Ph}+\% \text { (qualitative } \mathrm{PCR} \text { as } B C R-A B L: \beta_{2} M \text { ratio) at enrolment and during } \\
\text { CMLVAX100 vaccination }\end{array}$} \\
\hline & & & & CD4 & Interferon $\gamma$ & DTH & $\begin{array}{l}6 \text { months } \\
\text { before } \\
\text { vaccination }\end{array}$ & Baseline & $\begin{array}{l}1.5 \text { months } \\
\text { after } \\
3 \text { vaccinations }\end{array}$ & $\begin{array}{l}3 \text { months after } \\
6 \text { vaccinations }\end{array}$ \\
\hline \multicolumn{11}{|c|}{ Patients on imatinib } \\
\hline $1(0.98)$ & 24 & Relapse & DR11 & + & .. & - & $15 \%$ & $43 \%$ & ND & $37 \%$ \\
\hline $2(1.89)$ & 15 & $11(2-5 \%)$ & DR11, DR1 & + & .. & $+1-$ & $3 \%$ & $5 \%$ & ND & $4 \%$ \\
\hline $3(1)$ & 18 & $12(8-10 \%)$ & DR11 & + & & + & $10 \%$ & $10 \%(0.01)$ & $7 \%$ (ND) & $0 \%(0.008)$ \\
\hline $4(0.88)$ & 12 & $8(2-7 \%)$ & DR11, A3 & + & ND & + & $3 \%$ & $2 \%$ & $2 \cdot 5 \%$ & $0 \%(0.001)$ \\
\hline $5(1.14)$ & 14 & $10(8-10 \%)$ & DR11 & + &.. & + & $8 \%$ & $10 \%$ & $0 \%(0.003)$ & $0 \%(0.0000003)$ \\
\hline $6(n / a)$ & 12 & $6(5-10 \%)$ & $\mathrm{DR} 1, \mathrm{~A} 3$ & + & ND & + & $5 \%$ & $10 \%$ & $0 \%(0.015)$ & $0 \%(0.0000002)$ \\
\hline $7(0.98)$ & 20 & $16(3-4 \%)$ & $\mathrm{DR} 4, \mathrm{~A} 3$ & + & ND & + & $3 \%$ & $4 \%$ & $0 \%(0.0000006)$ & $0 \%(0.0000006)$ \\
\hline $8(0.73)$ & 14 & $10(20-25 \%)$ & DR1 & + &.. & + & $20 \%$ & $25 \%$ & $11 \%$ & $10 \%$ \\
\hline $9(1 \cdot 43)$ & 16 & $12(35-40 \%)$ & DR11 & + & .. & - & $35 \%$ & $40 \%$ & $40 \%$ & $20 \%$ \\
\hline $10(0.97)$ & 23 & $16(0 \%)$ & DR11 & + & & + & $0 \%$ & $0 \%(0.0001)$ & $0 \%$ (ND) & $0 \%(0.000065)$ \\
\hline \multicolumn{11}{|c|}{ Patients on interferon alfa } \\
\hline $1(1.02)$ & 28 & $12(5-10 \%)$ & DR11 & + & .. & + & $5 \%$ & $10 \%$ & $8 \%$ & $0 \%(0.001)$ \\
\hline $2(0.89)$ & 66 & $20(4-17 \%)$ & $A 3, B 8$ & ND & + & + & $4 \%$ & $17 \%$ & ND & $8 \%$ \\
\hline $3(0.78)$ & 88 & $22(7-16 \%)$ & A11, B8 & ND & + & - & $10 \%$ & $7 \%$ & ND & $3 \%$ \\
\hline $4(0.87)$ & 60 & $36(3-5 \%)$ & A3, DR11 & $+1-$ & + & + & $2 \%$ & $3 \%$ & $0 \%(0.14)$ & No metaphases $(0.052)$ \\
\hline $5(1 \cdot 32)$ & 48 & $13(30-33 \%)$ & A3, DR11 & + & $+1-$ & - & $30 \%$ & $33 \%$ & $25 \%$ & $100 \%$ \\
\hline $6(0.84)$ & 59 & $14(9-46 \%)$ & $A 3, D R 11$ & + & + & - & $25 \%$ & $46 \%$ & $0 \%(0.0003)$ & $3.3 \%(0.00018)$ \\
\hline
\end{tabular}


nested RT-PCR analysis, which gave negative results for the fused transcript. The only patient starting the vaccine protocol in stable CCR after six vaccinations showed a half-log reduction of his residual molecular disease as measured by real-time quantitative PCR.

All patients receiving interferon alfa for a median of 59 months (table 2) started vaccinations with a persistent cytogenetic residual disease (median 13\% Philadelphiachromosome-positive cells), remaining stable from 10 to 36 months (median 17 months). Of the six patients, five showed a reduction of their stable disease during vaccinations, with two reaching CCR. Furthermore, patient 1 also had a negative RT-PCR result after six vaccinations and subsequently a further 60 -fold reduction of $B C R-A B L: \beta_{2}$ microglobulin ratio after the first and second boosts. This molecular response was kept stable by use of six boosts (each at 6-month intervals), despite the fact that the patient first reduced interferon alfa at 3 MU per week and then definitively suspended interferon treatment after the third boost of vaccine.

Tolerance to CMLVAX100 was optimum, with patients mainly showing little discomfort at the vaccination site. Seven of 16 patients had mild fever after the first injection of molgramostim but none after CMLVAX100. Local redness, slight oedema, or itching were consistently seen after both vaccine and adjuvant injections. None of the patients delayed or suspended vaccinations because of general or cutaneous toxic effects.
14 of 16 patients had appropriate HLA class II molecules, whereas only eight presented one or more HLA class I molecules. Although all 16 patients were negative for delayed-type hypersensitivity reactions before vaccination, 11 showed positive results after six vaccinations, nine of which were positive after the first three vaccinations. We noted that all but one patient (interferon alfa patient 6) that reached CCR showed delayed-type hypersensitivity, whereas four of five hypersensitivity-negative patients still presented Philadelphia-chromosome-positive metaphases after six vaccinations (table 2 ).

All 14 patients with one or more appropriate HLA class II molecules were tested for the presence of b3a2peptide-specific CD4 T cells in freshly isolated, unprimed PBMC. Before vaccination, no patient showed positive responses in the presence of CMLVAX100 peptides compared with control or irrelevant peptides. Neither vaccine nor control-peptide-specific CD4 were recorded before vaccinations. However, after six vaccinations, 13 patients showed varying specific proliferation response in the presence of all five CMLVAX100 peptides (stimulation index range: $1 \cdot 5-16 \cdot 0$ ) or b3a2-25 peptide alone $(1 \cdot 8-25 \cdot 0)$. In particular, all patients on imatinib tested after six vaccinations presented a specific proliferation of CD4 cells (figure).

Similarly, of the four patients on interferon alfa treatment studied, three showed CD4-positive

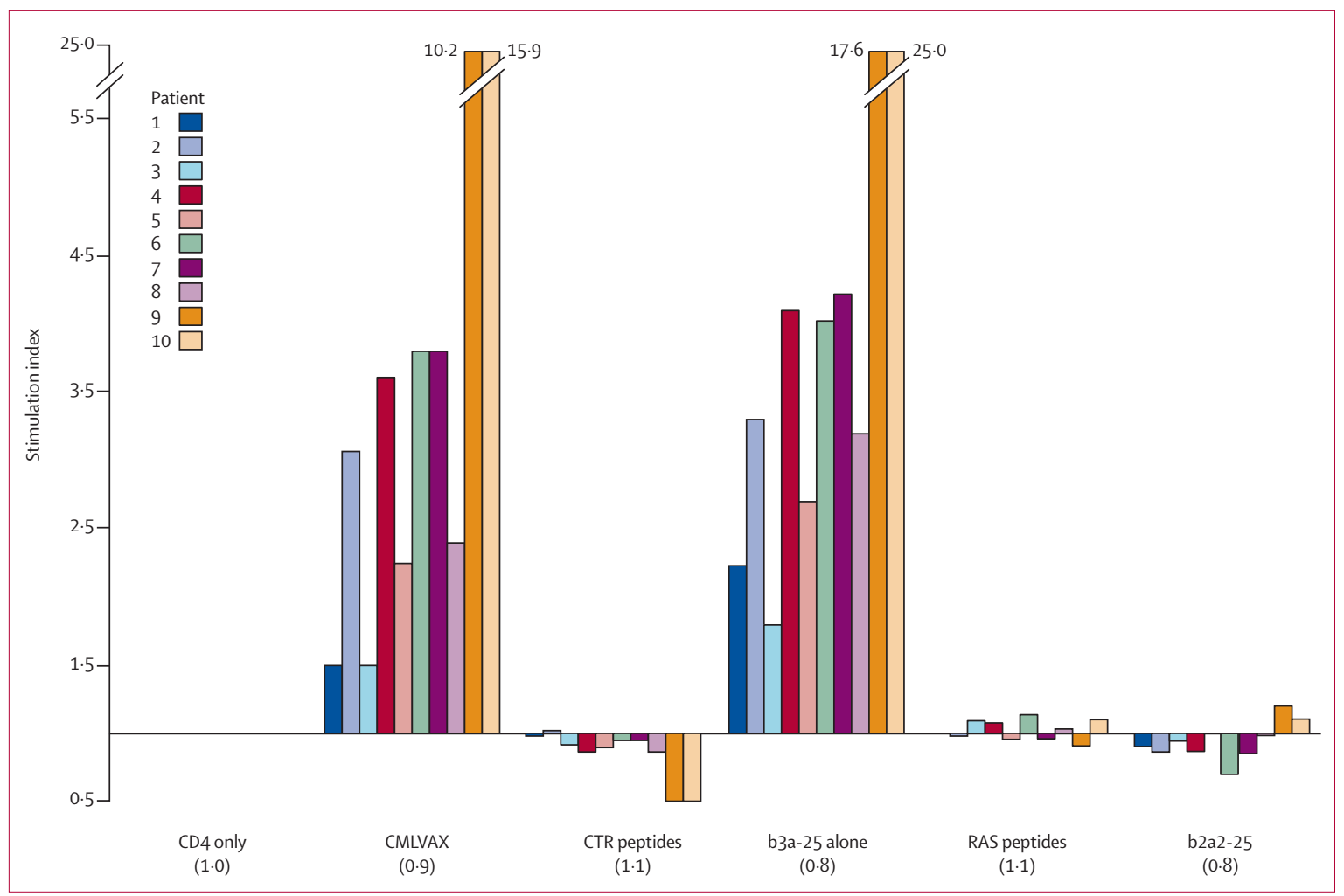

Figure: Induction of b3a2-25 peptide-specific CD4 cells after six CMLVAX100 vaccinations in patients on imatinib

Patients' identification numbers correspond to those on imatinib in table 2. Numbers in brackets are baseline median stimulation index. 


\begin{tabular}{|c|c|c|c|c|c|c|c|c|c|c|c|c|c|c|c|c|}
\hline & \multicolumn{16}{|c|}{ Peptide } \\
\hline & \multicolumn{2}{|c|}{ CMLVAX100 (five peptides) } & \multicolumn{2}{|c|}{ ) Control (five peptides) } & \multicolumn{2}{|c|}{ CML (A3/A11) } & \multicolumn{2}{|c|}{$\operatorname{HIV}(\mathrm{A} 3)$} & \multicolumn{2}{|c|}{$\operatorname{HIV}(\mathrm{A} 11)$} & \multicolumn{2}{|c|}{ CML (B8) } & \multicolumn{2}{|c|}{ CML (b3a2-25) } & \multicolumn{2}{|l|}{ RAS } \\
\hline & Pre & +6 & Pre & +6 & Pre & +6 & Pre & +6 & Pre & +6 & Pre & +6 & Pre & +6 & Pre & +6 \\
\hline \multicolumn{17}{|l|}{ Patient (HLA) } \\
\hline $2(A 3, B 8)$ & 5 & 104 & 7 & 0 & 3 & 68 & 6 & 0 & ND & ND & 9 & 51 & ND & ND & ND & ND \\
\hline $3(\mathrm{~A} 11, \mathrm{~B} 8)$ & 14 & 92 & 17 & 6 & 12 & 80 & 10 & ND & 15 & 52 & 17 & 108 & ND & ND & ND & ND \\
\hline $4(\mathrm{~A} 3, \mathrm{DR} 11)$ & 0 & 50 & 4 & 0 & 2 & 49 & 5 & 0 & 0 & 3 & ND & ND & 5 & 69 & 4 & 0 \\
\hline $5(A 3, D R 11)$ & 2 & 15 & 3 & 0 & ND & ND & 3 & 1 & ND & ND & ND & ND & 0 & 48 & 2 & 1 \\
\hline $6(\mathrm{~A} 3, \mathrm{DR} 11)$ & 12 & 134 & 13 & 11 & 15 & 126 & 14 & 17 & 16 & 13 & ND & ND & 8 & 156 & 9 & 49 \\
\hline
\end{tabular}

responses; after six vaccinations, although their CD4 cells did not proliferate alone or in the presence of control peptides, they showed stimulation index scores of $2 \cdot 8,3 \cdot 0$, and $5 \cdot 0$, in the presence of all five CMLVAX100 peptides and of $3 \cdot 0,3 \cdot 8$, and $8 \cdot 7$, respectively, in the presence of b3a2-25 peptides alone. In the first vaccinated patient (table 2 , patient 1 on interferon alfa) consistent b3a2-25-peptide-specific CD4 proliferation (stimulation index range 2-3) was maintained during six additional boosts of vaccine given every 6 months, thus an immune response specific to chronic myeloid leukaemia was still detectable 3 years after the initial vaccination protocol was completed (data not shown). With respect to clinical response, all but one patient with vaccine-induced positive CD4 immune reaction showed an improvement in cytogenetic disease, regardless of the noted stimulation index.

Whole PBMC from five vaccinated patients on interferon alfa treatment and who presented the appropriate MHC class I haplotype were analysed before and after six vaccinations. Before vaccination, these patients showed no or few T cells secreting interferon $\gamma$ in response to CMLVAX100 peptides (table 3). The number of spots in unstimulated PBMC ranged from 11 to 106 spots in $3 \times 10^{5}$ cells, with a median of 86 spotforming cells per $3 \times 10^{5}$ cells. However, the number of interferon- $\gamma$-secreting cells substantially increased in post-vaccination samples. In particular, all five patients showed a positive response when PBMC were incubated with all CMLVAX100 peptides, compared with five control peptides. Additionally, specific interferon $\gamma$ production was noted in the presence of one HLA-classI-matched short peptide only (A3/A11 or B8), a proper HLA class II molecule (DR11), and the b3a2-25 peptide alone (table 3).

\section{Discussion}

We report that the CMLVAX100 vaccine was very effective in inducing a specific immune response; almost $70 \%$ of patients had a positive delayed-type hypersensitivity reaction, and in all but one patient with appropriate HLA class II molecules we measured a consistent, albeit variable, in-vitro CD4 proliferative response to b3a2 peptides. Furthermore, more than half the patients with appropriate HLA class I molecules presented b3a2-peptide-specific interferon $\gamma$ production after vaccinations. The presence of a positive delayedtype hypersensitivity response seemed to correlate with the degree of residual-disease reduction.

Vaccinations with CMLVAX100 were followed by an antitumour effect in most patients. Most vaccinated patients showed a consistent reduction of their residual cytogenetic disease that had been assessed as stable for a median of 10 months preceding the vaccine. In particular, the fact that about half of patients on imatinib and on interferon alfa achieved CCR after six vaccinations (ie, in 3 months) is noteworthy. Patients who do not achieve CCR after 1 year of imatinib treatment still have a $20 \%$ likelihood to reach CCR at 24 months of therapy. ${ }^{26}$ However, the rapidity of response ( 3 months) that we recorded in all vaccinated patients who reached CCR and the undetectable amounts of $B C R-A B L$ transcripts in three of five patients on imatinib seems to be in favour of the vaccine as additional antileukaemic treatment.

A recent molecular data analysis from the International Randomized Study of Interferon versus STI571 (IRIS) ${ }^{25}$ showed that, overall, only $4 \%$ of patients on imatinib treatment who reached CCR had undetectable amounts of $B C R-A B L$ transcript. ${ }^{7}$ This percentage rose to $30 \%$ in early cytogenetic responders after 12-24 months of stable CCR. ${ }^{27}$ Again, our results are in contrast with a sole imatinib effect, because undetectable amounts of $B C R-A B L$ transcripts were achieved in a very short period in three patients who started vaccinations with residual metaphases.

Finally, we also emphasise that all but one patient on interferon alfa treatment showed improvement in their previously stable cytogenetic response, with a third reaching CCR and one patient reaching a negative qualitative standard RT-PCR status after two boosts of vaccine. ${ }^{28}$ Since these patients had had a stable disease for a median of 17 months and that they were on interferon alfa treatment for a median of 59 months, the prompt clinical effect was probably a result of the vaccinations. 
In conclusion, our preliminary data suggest that the addition of a b3a2-specific vaccine such as CMLVAX100 to b3a2-CML patients treated with conventional treatment might favour a further reduction of residual disease and increase the number of patients who reach a molecular response, the best surrogate of cure in patients with chronic myeloid leukaemia. Studies focused on improved assessment of residual disease with additional cytogenetic and molecular tests before and after vaccinations, including a larger cohort of patients as well as a longer follow-up than those of our own study with further boosts of vaccine, are in progress to assess definitively the role of this additive antileukaemic T-cell mediated immunotherapy.

\section{Contributors}

M Bocchia conceived and designed the study, supervised the immunological assays, obtained the clinical and laboratory data, and wrote the report. S Gentili, E Abruzzese, F Iuliano, A Tabilio, and S Amadori were responsible for patients' accrual and monitoring and management of the clinical data at their referring centre. M Amabile centralised the monitoring of the molecular responses to the vaccine.

A Fanelli, F Forconi, A Gozzetti, and D Raspadori undertook the assays and the monitoring of the immunological responses. F Lauria contributed to the design of the trial and supervised the study. All authors critically contributed to the final preparation of the article.

\section{Conflict of interest statement}

We declare that we have no conflict of interest.

Acknowledgments

This study was supported by grants from MIUR 2002-03, CNR/MIUR 2003, PAR 2003, SIENAIL, and Monte dei Paschi Foundation 2003.

\section{References}

1 Sawyers CL. Chronic myeloid leukemia. N Engl J Med 1999; 340: 1330-40.

2 Lugo TG, Pendergast AM, Muller AJ, Witte ON. Tyrosine kinase activity and transformation potency of $b c r-a b l$ oncogene products. Science 1990; 247: 1079-82.

3 Daley GQ, Van Etten RA, Baltimore D. Induction of chronic myelogenous leukemia in mice by the $2210 \mathrm{bcr} / \mathrm{abl}$ gene of the Philadelphia chromosome. Science 1990; 247: 824-30.

4 Druker BJ, Tamura S, Buchdunger E, et al. Effect of a selective inhibitor of the Abl tyrosine kinase on the growth of bcr-abl positive cells. Nat Med 1996; 2: 561-66.

5 Kantarjian H, Sawyers C, Hochhaus A, et al. Hematologic and cytogenetic responses to imatinib mesylate in chronic myelogenous leukemia. N Engl J Med 2002; 346: 645-52.

6 O'Brien SG, Guilhot F, Larson RA, et al. Imatinib compared with interferon and low-dose cytarabine for newly diagnosed chronicphase chronic myeloid leukemia. N Engl J Med 2003; 348: 994-1004.

7 Hughes TP, Kaeda J, Branford S, et al. Frequency of major molecular responses to imatinib or interferon alfa plus cytarabine in newly diagnosed chronic myeloid leukemia. N Engl J Med 2003; 349: 1423-32.

8 Weisberg E, Griffin JD. Mechanism of resistance to the ABL tyrosine kinase inhibitor STI571 in BCR/ABL-transformed hematopoietic cell lines. Blood 2000; 95: 3498-505.

9 Mahon FX, Deininger MW, Schultheis B, et al. Selection and characterization of BCR/ABL positive cell lines with differential sensitivity to the tyrosine kinase inhibitor STI571: diverse mechanisms of resistance. Blood 2000, 96: 1070-79.

10 Bhatia R, Holtz M, Niu N, et al. Persistence of malignant hematopoietic progenitors in chronic myelogenous leukemia patients in complete cytogenetic remission following imatinib treatment. Blood 2003; 101: 4701-07.
11 Bocchia M, Wentworth PA, Southwood S, et al. Specific binding of leukemia oncogene fusion protein peptide to HLA class I molecules. Blood 1995; 85: 2680-84.

12 Bosh GJ, Joosten AM, Kessler JH, Melief CJ, Leeksma OC Recognition of BCR-ABL positive leukemia blast by human CD4+ T cells elicited by primary in vitro immunization with a BCR-ABL breakpoint peptide. Blood 1996; 88: 3522-27.

13 Bocchia M, Korontsvit T, Xu Q, et al. Specific human cellular immunity to $B C R-A B L$ oncogene-derived peptides. Blood 1996; 87: 3587-92.

14 Greco G, Fruci D, Accapezzato D, et al. Two bcr-abl junction peptides bind to HLA A3 molecules and allow specific induction of human cytotoxic T lymphocytes. Leukemia 1996; 10: 693-99.

15 Norbury LC, Clark RE, Christmas SE. b3a2 BCR-ABL fusion peptides as targets for cytotoxic $\mathrm{T}$ cells in chronic myeloid leukemia. Br J Haematol 2000; 109: 616-21.

16 Yasukawa M, Ohminami H, Kojima K, et al. HLA class II-restricted antigen presentation of endogenous brc-abl fusion protein by chronic myelogenous leukemia-derived dendritic cells to CD4+ T lymphocytes. Blood 2001; 98: 1498-505.

17 Livingston PO, Adhuri S, Helling F, et al. Phase I trial of immunological adjuvant QS-21 with a GM2 ganglioside-keyhole limpet haemocyanin conjugate vaccine in patients with malignant melanoma. Vaccine 1994; 12: 1275-80.

18 Pinilla-Ibarz J, Cathcart K, Korontsvit T, et al. Vaccination of patients with chronic myelogenous leukemia with $b c r-a b l$ oncogene breakpoint fusion peptides generates specific immune response. Blood 2000; 95: 1781-87.

19 Cathcart K, Pinilla-Ibarz J, Korontsvit T, et al. A multivalent bcr-abl fusion peptide vaccination trial in patients with chronic myeloid leukemia. Blood 2003; 103: 1037-42.

20 Dísis ML, Bemhard H, Shiota FM, et al. Granulocyte-macrophage colony-stimulating factor: an effective adjuvant for protein and peptide-based vaccines. Blood 1996; 88: 202-10.

21 Slingluff CL Jr, Petroni GR, Yamshchikov GV, et al. Clinical and immunologic results of a randomized phase II trial of vaccination using four melanoma peptides either administer in granulocytemacrophage colony-stimulating factor in adjuvant or pulsed dentritic cells. J Clin Oncol 2003; 21: 4116-26.

22 Belli F, Testori A, Rivoltini L, et al. Vaccination of metastatic melanoma patients with autologous tumor-derived heat shock protein gp96-peptide complexes: clinical and immunologic findings. J Clin Oncol 2002; 20: 4169-80.

23 Amabile M, Giannini B, Testoni N, et al. Real-time quantification of different types of $b c r-a b l$ transcript in chronic myeloid leukemia. Haematologica 2001; 86: 252-59.

24 Gabert J, Beillard E, van der Velden VHJ, et al. Standardization and quality control studies of real-time quantitative reverse transcriptase polymerase chain reaction of fusion gene transcripts for residual disease detection in leukemia: a Europe Against Cancer Program. Leukemia 2003; 17: 2318-57.

25 Baccarani M, Rosti G, de Vivo A, et al. A randomised study of interferon alpha versus interferon-alpha and low-dose arabinosyl cytosine in chronic myeloid leukaemia. Blood 2002; 99: 1527-35.

26 Druker BJ, Gathmann I, Bolton AE, Larson RA, on behalf of the IRIS (International Randomized IFN vs STI571) study group. Probability and impact of obtaining a cytogenetic response to Imatinib as initial therapy for chronic myeloid leukaemia (CML) in chronic phase. Blood 2003; 102: 182a (abstr).

27 Rosti G, Martinelli G, Bassi S, et al. Molecular response to imatinib in late chronic-phase chronic myeloid leukemia. Blood 2004; 103: 2284-90.

28 Bocchia M, Gentili S, Lauria F. Is there any role left for p210derived peptide vaccines in chronic myeloid leukemia? Haematologica 2002; 87: 675-77. 